\title{
QUALIDADE FISIOLÓGICA DE SEMENTES DE MILHO EM FUNÇÃO DA FORMA E DO TRATAMENTO QUÍMICO DAS SEMENTES
}

\author{
PHYSIOLOGICAL QUALITY OF CORN SEEDS IN RELATION \\ TO SHAPE AND CHEMICAL TREATMENT
}

Líder Ayala Aguilera ${ }^{1}$ Braulio Otomar Caron ${ }^{2}$ Willyans Luiz Cella ${ }^{3}$ Ivo Lersch Junior ${ }^{4}$

\section{RESUMO}

As sementes de milho apresentam forma e tamanho diferenciados na espiga. No beneficiamento, as sementes são separadas em função dessas características, sendo que elas determinam as regulagens de semeadoras, afetam o tipo e a quantidade de danos mecânicos e o tratamento químico das sementes. Este trabalho teve por objetivo estudar os efeitos da forma $e$ do tratamento químico, na qualidade fisiológica de sementes do milho híbrido, super precoce PIONEER-32R21, produzidas na safra 1997/98. As sementes foram separadas em peneiras de crivos circulares, de 8,73mm e 7,93mm de diâmetro. Sementes retidas na segunda peneira sofreram uma nova classificação na peneira de crivos oblongos de 5,1mm x 20mm. Dessa maneira, obtiveram-se sementes selecionadas quanto à forma, em sementes esféricas e achatadas. Metade das sementes receberam tratamento químico com a mistura dos seguintes produtos na suas formas comerciais: Captam $75 \%$, Deltamethrina $2.5 \%$ e Pirimiphos metil 50\%, na dose de 1,0g, 0,08ml e 0,03ml por $\mathrm{kg}$ de semente, respectivamente, constituindo assim os seguintes lotes: sementes esféricas tratadas, sementes esféricas não tratadas, sementes achatadas tratadas e sementes achatadas não tratadas. Os lotes foram avaliados pelo teste padrão de germinação e pelos seguintes testes de vigor: teste de envelhecimento acelerado, teste de frio e teste de condutividade elétrica. $O$ delineamento utilizado foi inteiramente casualizado com arranjo bifatorial $2 \times 2$, com duas formas das sementes e sementes com e sem tratamento químico, com quatro repetições. Os resultados indicaram que as sementes achatadas apresentam maior qualidade fisiológica do que as sementes esféricas, e que as sementes achatadas tratadas tem melhor desempenho no teste de frio, do que as sementes esféricas tratadas. $O$ tratamento químico permite a obtenção de maior percentagem de germinação de sementes de milho.
Palavras-chave: germinação, tamanho de sementes, tratamento químico, vigor de sementes, Zea mays.

\section{SUMMARY}

The corn seeds present form and size in the spike. In the processing, the seeds are separate in function of these characteristics, and these determine regulates adjustments, they affect the type and the amount of mechanical damages, and the chemical treatment. The objective of this work was to study the effects of seed shape and chemical treatment on physiological seed quality of the hybrid corn seed "PIONEER - 32R21" produced in 1997/1998. As to obtain seeds of round and of plane shapes, seeds were separated by round screens of $8.75 \mathrm{~mm}$ and $7.93 \mathrm{~mm}$ respectively and then by an oblong screen of $5.1 \mathrm{~mm} x$ $20 \mathrm{~mm} .50 \%$ of the separated seeds were treated with a mixture of Captam (75\%) using a dose of $1.0 \mathrm{~g} / \mathrm{kg}$ seed, Deltamethrina (2.5\%) $0.08 \mathrm{ml} / \mathrm{kg}$ seed and Pirimiphos metil $(50 \%) 0.03 \mathrm{ml} / \mathrm{kg}$ seed, resulting in: treated round seeds, untreated round seeds, plane treated seeds and plane untreated seeds. Germination and vigor were evaluated, using electric conductivity, cold test and artificial aging. The experiment design was completely randomized with four replications ( $2 x 2$ factorial) each treatment. The results showed that plane seeds of PIONEER-32R21, have better physiological quality than round seeds. Plane seeds reacted significantly better on the chemical treatment than round seeds as determined by cold test. Chemical treatment, in general, favors corn seed germination.

Key words: germination, chemical treatment, seed vigor, seed size, Zea mays.

\footnotetext{
${ }^{1}$ Engenheiro Agrônomo, Mestre, aluno de doutorado do Curso de Ciência e Tecnologia de Sementes. Faculdade de Agronomia "Eliseu Maciel"(FAEM), Universidade Federal de Pelotas (UFPEL).

${ }^{2}$ Engenheiro Agrônomo, Mestre, aluno de doutorado, Programa de Pós-graduação em Agronomia, Universidade Federal de Santa Maria (UFSM), Departamento de Fitotecnia, UFSM, 97105-900, Santa Maria, RS. E-mail: a9960445@alunop.ufsm.br. Autor para correspondência.

${ }^{3}$ Engenheiro Agrônomo, Mestre.

${ }^{4}$ Engenheiro Agrônomo, estudante do Programa de Pós-graduação em Agronomia, Universidade Federal de Santa Maria (UFSM). Santa Maria, RS.
} 


\section{INTRODUÇÃO}

O milho é produzido em todo o território nacional. Sua grande capacidade de adaptação, aliada a sua utilidade, faz com que seja a cultura mais disseminada. No Rio Grande do Sul, 30\% do total das áreas semeadas com cultivos de primavera-verão e 35\% da produção total anual de grãos é milho, perfazendo $16,4 \%$ da produção nacional, sendo que o Estado desponta como segundo maior produtor, apresentando um rendimento médio de $3 \mathrm{t} \mathrm{ha}^{-1}$.

Para manutenção dos níveis de rendimentos alcançados, assim como para aumentá-los, conforme exigem as projeções crescentes da população, há necessidade de uso de tecnologias com reflexos diretos sobre a produtividade agrícola, dentre os quais se pode destacar utilização de sementes de alta qualidade.

A semente é um dos principais insumos da agricultura e sua qualidade é um dos fatores primordiais ao estabelecimento de qualquer cultura. A qualidade de sementes é um somatório de todos os atributos genéticos, físicos, fisiológicos e sanitários que afetam a capacidade da semente em originar plantas de alta produtividade (POPINIGIS, 1985).

É extremamente desejável nas sementes de milho a uniformidade de forma e tamanho, para facilitar tratamentos químicos e a semeadura; porém, existe grande variação na uniformidade das sementes na própria espiga, quanto à forma e tamanho, o que torna necessária a classificação pela largura, espessura e comprimento.

Buscando a uniformização, as sementes de milho são classificadas de acordo com sua forma (esférica e achatada) e tamanho, favorecendo dessa maneira a comercialização, o tratamento químico e a regulagem do equipamento utilizado na semeadura. Existe uma grande polêmica quanto à influência do tamanho no processo germinativo de sementes. Vários autores (SCOTTI \& KRZYZANOWSKI, 1977; SHIEH \& McDONALD, 1982; Von PINHO et al., 1995) encontraram maiores percentagens de germinação e vigor (testes de laboratório) para sementes grandes, não se manifestando tais diferenças no campo. Porém, SHIEH \& McDONALD (1982) constataram que as sementes achatadas e as tratadas apresentaram qualidade superior às não tratadas $\mathrm{e}$ arredondadas. Por outro lado, COSTA \& CARVALHO (1983) e SCOTTI \& SILVEIRA (1977) não encontraram diferenças significativas no tamanho das sementes, quanto à germinação e outras características. ANDRADE et al. (1997) constataram que o tamanho e a forma das sementes não afetaram o desenvolvimento das plantas, inclusive na produção de grãos, acrescentando que o uso de sementes menores acarreta economia de até $44 \%$ na quantidade de sementes a ser adquirida para a semeadura.

Atualmente, o uso de fungicidas e inseticidas em sementes de milho é necessário, principalmente, devido ao longo período de armazenamento e às condições deste, ou seja, ocorrência de pragas e fungos de armazenamento, que são facilmente detectados em nossas condições. O tratamento químico visa ao armazenamento, mas possui algum efeito na semeadura feita em solos com temperaturas amenas e em condições que retardam a germinação das sementes (PEREIRA, 1986). Um dos meios mais eficientes de disseminação de doenças é a semente, considerandose que é através dela que os patógenos podem ser transportados a grandes distâncias e introduzidos em novas áreas (NEEGAARD, 1979). Existe um grande número de produtos a serem utilizados no tratamento de sementes, especificados conforme o microorganismo patogênico. Para controle eficiente, a utilização de misturas é uma técnica aconselhável, desde que possível, com objetivo de buscar controle de um maior espectro de fungos, sendo que no milho, segundo PEREIRA (1986), os fungos mais encontrados em sementes são Fusarium moniliforme, Aspergillus ssp. e Penicillium sp. Von PINHO et al. (1995) encontraram melhores resultados para sementes de milho tratadas com os fungicidas Halt 50, TCMTB, Captan e Metalaxyl + Thiabendazole, para Fusarium moniliforme, Aspergillus spp. e Penicillium sp., em teste de germinação e emergência de plântulas no teste de frio. Já sementes de alto vigor apresentaram pequena resposta ao tratamento com fungicida no teste de emergência em campo. Deve-se tomar maiores cuidados com grupos de fungicidas que podem se mostrar fitotóxico à semente, retardando a emergência e proporcionando aparecimento de plântulas retorcidas, espessas e alargadas (GOULART, 1993).

Dessa maneira, este trabalho teve por objetivo estudar os efeitos da forma e do tratamento químico, na qualidade fisiológica de sementes de milho.

\section{MATERIAL E MÉTODOS}

O experimento foi realizado no Laboratório de Análise de Sementes de Produção do Departamento de Fitotecnia, do Centro de Ciências Rurais / UFSM, Santa Maria / RS, no período de junho julho de 1998.

Sementes do híbrido super precoce 32R21, produzidas na safra 1997/98 foram obtidas 
junto à empresa PIONEER LTDA. No primeiro processo de classificação, as sementes foram separadas em peneiras de crivos circulares de $8,73 \mathrm{~mm}$ e $7,93 \mathrm{~mm}$ de diâmetro. As sementes que ficaram retidas na segunda peneira, sofreram novamente uma classificação na peneira de crivos oblongos de $5,1 \mathrm{~mm}$ x $20 \mathrm{~mm}$. Dessa maneira, obtiveram-se sementes selecionadas quanto à forma, sementes esféricas e achatadas. Metade das sementes, de cada uma das formas, receberam tratamento químico com a mistura dos seguintes produtos na sua forma comercial: Captam 75\%, Deltamethrina $2.5 \%$ e Pirimiphos metil $50 \%$, na dose de $1,0 \mathrm{~g}, 0,08 \mathrm{ml}$ e $0,03 \mathrm{ml}$ por $\mathrm{kg}$ de semente, respectivamente. Após separação pela forma e o tratamento químico, as sementes constituíram os seguintes lotes: SET (sementes esféricas tratadas), SEN (sementes esféricas não tratadas), SCT (sementes achatadas tratadas) e SCN (sementes achatadas não tratadas).

Os efeitos da forma e do tratamento químico das sementes sobre a qualidade fisiológica foram avaliados pelo teste padrão de germinação (TPG), o qual foi realizado conforme indicação das Regras para Análise de Sementes (BRASIL, 1992), em papel germitest umedecido com água equivalente a 2,5 vezes seu peso, com quatro repetições de 50 sementes, em germinador a $30^{\circ} \mathrm{C}$ durante sete dias e pelos seguintes testes de vigor: a) teste de envelhecimento acelerado realizado de acordo com as recomendações de MARCOS FILHO (1994), usando-se quatro repetições de 50 sementes para cada tratamento; as sementes foram distribuídas sobre um suporte telado de arame galvanizado e colocadas em caixas gerbox com $40 \mathrm{ml}$ de água destilada, permanecendo na câmara de envelhecimento a $42^{\circ} \mathrm{C}$, por 96 horas; imediatamente, após a exposição as sementes foram submetidas ao TPG e avaliadas no quinto dia; b) teste de frio, conduzido em caixas plásticas, com quatro repetições de 50 sementes para cada lote e, como substrato, uma mistura de 2 partes de solo e 1 de areia, colocada em câmara fria a $5^{\circ} \mathrm{C}$ por sete dias; após esse período, as caixas foram levadas a um germinador regulado a $30^{\circ} \mathrm{C}$, onde permaneceram por cinco dias antes da avaliação final; c) condutividade elétrica, utilizando-se o condutivímetro, foi realizada seguindo as recomendações descritas por VIEIRA (1994), usando quatro repetições de 25 sementes para cada tratamento; as sementes foram pesadas e colocadas em copos plásticos de $250 \mathrm{ml}$, contendo $75 \mathrm{ml}$ de água destilada, permanecendo em estufa regulada à temperatura constante de $25^{\circ} \mathrm{C}$, por 24 horas; em seguida, foi lida a condutividade elétrica, com resultado expresso em $\mu \mathrm{s} / \mathrm{cm} / \mathrm{g}$ de semente.
O delineamento utilizado foi inteiramente casualizado com arranjo bifatorial $2 \times 2$, (duas formas das sementes, e sementes com e sem tratamento químico), com quatro repetições. Os dados originais em $\%$ foram transformados em arcsen $(\mathrm{p} / 100)^{1 / 2}$ e submetidos à análise estatística pelo programa SOC (EMBRAPA), sendo as médias comparadas pelo teste de Duncan a $1 \%$ de probabilidade de erro.

\section{RESULTADOS E DISCUSSÃO}

Pela tabela 1, observa-se que houve diferenças dentro dos níveis do fator forma, sendo melhores as sementes achatadas que as esféricas. As sementes tratadas tiveram uma percentagem maior de germinação quando comparadas com as sementes não tratadas, evidenciando o benefício do tratamento químico. Esses resultados concordam com SHIEH \& McDONALD (1982), que constataram que as sementes tratadas e as achatadas apresentaram qualidade superior às não tratadas e arredondadas.

$\mathrm{Na}$ tabela 2, observa-se que houve interação entre os fatores estudados, sendo que as sementes achatadas e tratadas (SCT) apresentaram maior vigor do que as sementes esféricas tratadas (SET). Para as sementes não tratadas, a diferença de forma não estabeleceu diferenças estatísticas no desempenho dos lotes. Por outro lado, as SCT apresentaram uma percentagem maior de plântulas quando comparadas com as sementes achatadas não tratadas ( $\mathrm{SCN}$ ), evidenciando uma vez mais o efeito do tratamento químico. As sementes esféricas não tratadas (SEN) tiveram melhor desempenho que as sementes esféricas tratadas (SET), pois apresentaram no teste de frio, maior número de plântulas normais, desse modo contrariando o esperado.

No teste de condutividade elétrica (Tabela 3) verificou-se diferença entre as médias dos níveis do fator tratamento, no qual as sementes tratadas

Tabela 1 - Germinação (\%) de sementes de milho em função da forma e do tratamento químico das sementes. Santa Maria, RS. 1998.

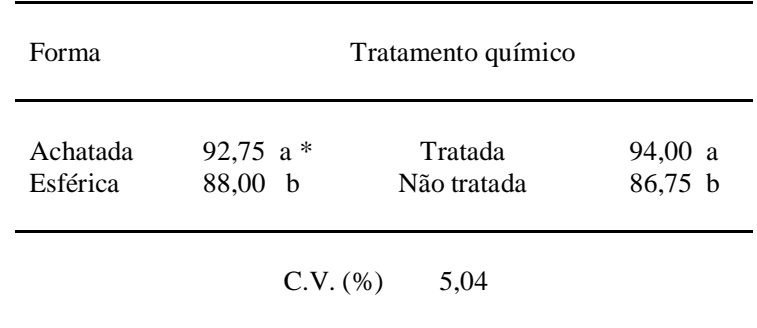

* - Tratamentos com médias não seguidas por mesma letra na vertical, diferem significativamente entre si, pelo teste de F a $1 \%$ de probabilidade de erro. 
Tabela 2 - Teste de frio (\%) realizado em sementes de milho em função da forma e do tratamento químico das sementes. Santa Maria, RS. 1998.

\begin{tabular}{|c|c|c|c|}
\hline \multirow[t]{2}{*}{ Tratamento } & \multicolumn{3}{|c|}{ Forma } \\
\hline & Achatada & Esfe & ica \\
\hline $\begin{array}{l}\text { Tratada } \\
\text { Não Tratada }\end{array}$ & $\begin{array}{l}97,50 \text { A* }^{*} \text { a } \\
96,50 \text { B a }\end{array}$ & $\begin{array}{l}87,00 \\
92,00\end{array}$ & $\begin{array}{ll}\mathrm{B} & \mathrm{b} \\
\mathrm{A} & \mathrm{a}\end{array}$ \\
\hline
\end{tabular}

C.V. (\%) 2,28

* - Tratamentos com médias não seguidas por mesma letra, maiúscula na vertical e minúscula na horizontal, diferem significativamente entre si pelo teste de Duncan a $1 \%$ de probabilidade de erro.

apresentaram valores mais altos de condutividade do que as não tratadas. Essa diferença deve-se à liberação de produtos químicos para a solução, interferindo na comparação entre lotes de sementes tratadas e não tratadas. Esse tratamento pode mascarar comparações de vigor entre lotes de sementes tratadas e não tratadas, indicando que, nesses casos, dever-seia usar outros testes para determinação do vigor de sementes. Houve diferença entre as médias das sementes esféricas e achatadas, onde estas apresentam valor de condutividade menor, indicando um vigor mais alto.

$\mathrm{Na}$ tabela 4, estão apresentados os resultados referentes ao teste de envelhecimento acelerado, onde se verificam diferenças entre os níveis do fator forma. As sementes achatadas apresentaram maior vigor do que as sementes esféricas, confirmando os resultados obtidos nos testes anteriores deste trabalho, e discordando com aqueles obtidos

Tabela 3 - Condutividade elétrica $(\mu \mathrm{s} / \mathrm{cm} / \mathrm{g})$ realizada em sementes de milho em função da forma e tratamento químico das sementes. Santa Maria, RS. 1998.

\begin{tabular}{lcccc}
\hline Forma & \multicolumn{3}{c}{ Tratamento químico } \\
\hline Esférica & $\begin{array}{c}18,89 \\
\text { Achatada }\end{array}$ & $\begin{array}{l}17,42 \\
\text { b }\end{array}$ & $\begin{array}{c}\text { Tratada } \\
\text { Não tratada }\end{array}$ & $\begin{array}{c}19,21 \quad \text { a } \\
17,10 \quad b\end{array}$ \\
\hline & C.V. $(\%)$ & 6,48 \\
\hline
\end{tabular}

* - Tratamentos com médias não seguidas por a mesma letra na vertical diferem significativamente pelo teste de F a $1 \%$ de probabilidade de erro.
Tabela 4 - Percentagem de plântulas normais no teste de envelhecimento acelerado realizado em sementes de milho em função da forma e tratamento químico das sementes. Santa Maria, RS. 1988

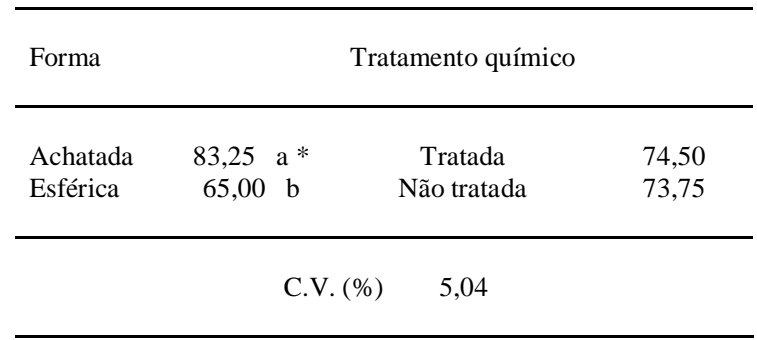

* - Tratamentos com médias não ligadas por mesma letra na vertical, diferem significativamente entre si, pelo teste de F a $1 \%$ de probabilidade de erro.

por ANDRADE $\boldsymbol{e t}$ al. (1997). Os resultados deste teste indicam que a qualidade das sementes achatadas se conservara melhor durante o armazenamento.

\section{CONCLUSÕES}

Para o milho híbrido, super precoce PIONEER 32-R21, as sementes achatadas apresentaram maior qualidade fisiológica do que as sementes esféricas. Apresentaram ainda, melhor desempenho no teste de frio quando receberam tratamento químico. O tratamento químico das sementes, realizado com a mistura de Captam 75\%, Deltamethrina 2,5\% e Pirimiphos metil $50 \%$, permitiu a obtenção de maior percentegem de germinação de sementes de milho.

\section{REFERÊNCIAS BIBLIOGRÁFICAS}

ANDRADE, R.V., ANDREOLI, C., BORBA, C.S., et al. Efeito da forma e do tamanho da semente no desempenho no campo de dois genótipos de milho. Revista Brasileira de Sementes, Brasília, v.19, n.1, p.62-65, 1997.

BRASIL. Ministério da Agricultura e Reforma Agrária. Regras para análise de sementes. Brasília : SNDA/CLAV, 1992. $365 \mathrm{p}$.

COSTA, C.L.V., CARVALHO, N.M. Efeito do tamanho sobre o comportamento de sementes de milho submetidas ao envelhecimento artificial. Revista Brasileira de Sementes, Brasília, v.5, n.2, p.23-27, 1983.

GOULART, A.C.P. Tratamento de sementes de milho (Zea mays L.) com fungicidas. Revista Brasileira de Sementes, Brasília, v.15, n.2, p.165-169, 1993.

MARCOS FILHO, J. Teste de envelhecimento precoce In: VIEIRA, R.D. \& CARVALHO, N.M. de. Testes de vigor em sementes. Jaboticabal : FUNEP, 1994. p.133-149.

NEEGAARD, P. Seed pathology. London : McMillan, 1979. v.1. $839 \mathrm{p}$. 
PEREIRA, O.A.P. Tratamento de sementes de milho. In: SIMPÓSIO BRASILEIRO DE PATOLOGIA DE SEMENTES, 2., 1986, Campinas. Palestras... Campinas : Fundação Cargill, 1986. p.145-148.

POPINIGIS, F. Controle de qualidade de sementes. In : CONGRESSO BRASILEIRO DE SEMENTES, 4., 1985, Brasília. Fisiologia da semente... Brasília : AGIPLAN, 1985. p.157. 289p.

SCOTTI, C.A., SILVEIRA, J.F. Tamanho da semente em relação ao comportamento do milho. Boletim Técnico Agronômico do Paraná, Londrina, v.4, p.1-12, 1977.

SCOTTI, C.A., KRZYSANOWSKI, F.C. Influência do tamanho da semente sobre a germinação e vigor em milho. Boletim Técnico Agronômico do Paraná, Londrina, v.5, p.1-10, 1977.

SHIEH, W.J. McDONALD, M.B. The influence of seed size, shape and treatment on inbred seed corn quality. Seed Science and Technology, Zürich, v.10, n.2, p.307-313, 1982.

VIEIRA, R.D. Teste de condutividade elétrica. In : VIEIRA, R.D., CARVALHO, N.M. de. Testes de vigor em sementes. Jaboticabal : FUNEP, 1994. p.103-132.

Von PINHO, E.V.R., CAVARIANI, C., ALEXANDRE, A.D., et al. Efeito do tratamento fungicida sobre a qualidade sanitária e fisiológica de sementes de milho (Zea mays L.). Revista Brasileira de Sementes, Brasília, v.17, n.1, p.23-28, 1995.

Ciência Rural, v. 30, n. 2, 2000. 